\title{
Linear Algebra Online and Offline: The 2015 Lin Lectures
}

\section{by Gilbert Strang*}

Lin Chia-Chiao was a remarkable man. He was very kind to this young assistant professor at MIT. All the faculty knew that he had come from China's famous university Tsinghua (and we were told that Tsinghua was the "MIT of China"). But I never expected to have this chance for lectures in his memory right here.

Everyone was permitted to call him C. C. His specialties were fluid mechanics and astrophysics. He was promoted to the rank of Institute Professor, which is an enormous honor at MIT. (The one and only Institute Professor in our department right now is Isadore Singer, winner of the Abel Prize jointly with Michael Atiyah.) After retirement C. C. and his wife eventually moved to a home provided for them here on the Tsinghua campus. On my previous visit I had the good fortune to talk to him-we enjoyed remembering the MIT Math Department of Wiener and Levinson and Lin. He passed away at the age of 96.

I was always grateful to him, and now it is a special honor to visit Tsinghua. I chose to speak partly about my experience of preparing video lectures on linear algebra. I want to encourage others to think (and to act!) in this direction too-it can change your life. I will also describe a sequence of ideas that could help to complete large matrices when data is missing, and to compute with those matrices when the size of the data is overwhelming.

\section{OpenCourseWare and Online Teaching}

My principal courses at MIT are 18.06 Linear Algebra and 18.085 Computational Science and Engineer-

* Department of Mathematics, Massachusetts Institute of Technology, Cambridge, Mass., U.S.A.

E-mail: gs@math.mit.edu ing. One is for undergraduates, with 250 students in Spring 2015. The other is for graduate students, with 125 students in Fall 2014. At some time in the 20th century I was asked to reorganize these subjects. At that time linear algebra was studied by a small group of math majors (which once included me-I liked it but we almost never saw a matrix). And the equivalent to 18.085 never saw a computer. This had to change-without losing the mathematical content.

The new courses needed new textbooks: Linear Algebra and Its Applications (1976 ... 2006) was followed by Introduction to Linear Algebra (WellesleyCambridge Press, 1993 ... 2009). A Chinese translation of that second book is just completed. For the graduate course, Introduction to Applied Mathematics (1986) was followed by Computational Science and Engineering (2007). And now there are video lectures; those are my subject today.

MIT's OpenCourseWare was a new answer to an old question: How to help students outside the classroom? It was the right answer-to make the lectures free for everyone. There are 2000 MIT courses on ocw.mit.edu, many with videos. They show MIT as it is.

The new problem in 2015 is to go further. OCW led to MITx (on campus) and edX (worldwide) with homeworks and exams and grades and certificates. The 18.06 homeworks are now graded by computer, with instant response that students like. We have not yet offered an edX course on linear algebra (a MOOC = Massive Open Online Course).

The linear algebra course was filmed in my normal class with normal mistakes; you could look at Lecture 10. Probably 4,000,000 viewers have watched, and quite a large subset has sent email! I especially wanted to provide a version with Chinese subtitles. 


\section{Linear Algebra Online and Offline: The 2015 Lin Lectures}

\section{by Gilbert Strang*}

Lin Chia-Chiao was a remarkable man. He was very kind to this young assistant professor at MIT. All the faculty knew that he had come from China's famous university Tsinghua (and we were told that Tsinghua was the "MIT of China"). But I never expected to have this chance for lectures in his memory right here.

Everyone was permitted to call him C. C. His specialties were fluid mechanics and astrophysics. He was promoted to the rank of Institute Professor, which is an enormous honor at MIT. (The one and only Institute Professor in our department right now is Isadore Singer, winner of the Abel Prize jointly with Michael Atiyah.) After retirement C. C. and his wife eventually moved to a home provided for them here on the Tsinghua campus. On my previous visit I had the good fortune to talk to him-we enjoyed remembering the MIT Math Department of Wiener and Levinson and Lin. He passed away at the age of 96.

I was always grateful to him, and now it is a special honor to visit Tsinghua. I chose to speak partly about my experience of preparing video lectures on linear algebra. I want to encourage others to think (and to act!) in this direction too-it can change your life. I will also describe a sequence of ideas that could help to complete large matrices when data is missing, and to compute with those matrices when the size of the data is overwhelming.

\section{OpenCourseWare and Online Teaching}

My principal courses at MIT are 18.06 Linear Algebra and 18.085 Computational Science and Engineer-

* Department of Mathematics, Massachusetts Institute of Technology, Cambridge, Mass., U.S.A.

E-mail: gs@math.mit.edu ing. One is for undergraduates, with 250 students in Spring 2015. The other is for graduate students, with 125 students in Fall 2014. At some time in the 20th century I was asked to reorganize these subjects. At that time linear algebra was studied by a small group of math majors (which once included me-I liked it but we almost never saw a matrix). And the equivalent to 18.085 never saw a computer. This had to change-without losing the mathematical content.

The new courses needed new textbooks: Linear Algebra and Its Applications (1976 ... 2006) was followed by Introduction to Linear Algebra (WellesleyCambridge Press, 1993 ... 2009). A Chinese translation of that second book is just completed. For the graduate course, Introduction to Applied Mathematics (1986) was followed by Computational Science and Engineering (2007). And now there are video lectures; those are my subject today.

MIT's OpenCourseWare was a new answer to an old question: How to help students outside the classroom? It was the right answer-to make the lectures free for everyone. There are 2000 MIT courses on ocw.mit.edu, many with videos. They show MIT as it is.

The new problem in 2015 is to go further. OCW led to MITx (on campus) and edX (worldwide) with homeworks and exams and grades and certificates. The 18.06 homeworks are now graded by computer, with instant response that students like. We have not yet offered an edX course on linear algebra (a MOOC = Massive Open Online Course).

The linear algebra course was filmed in my normal class with normal mistakes; you could look at Lecture 10. Probably 4,000,000 viewers have watched, and quite a large subset has sent email! I especially wanted to provide a version with Chinese subtitles. 


\section{Linear Algebra Online and Offline: The 2015 Lin Lectures}

\section{by Gilbert Strang*}

Lin Chia-Chiao was a remarkable man. He was very kind to this young assistant professor at MIT. All the faculty knew that he had come from China's famous university Tsinghua (and we were told that Tsinghua was the "MIT of China"). But I never expected to have this chance for lectures in his memory right here.

Everyone was permitted to call him C. C. His specialties were fluid mechanics and astrophysics. He was promoted to the rank of Institute Professor, which is an enormous honor at MIT. (The one and only Institute Professor in our department right now is Isadore Singer, winner of the Abel Prize jointly with Michael Atiyah.) After retirement C. C. and his wife eventually moved to a home provided for them here on the Tsinghua campus. On my previous visit I had the good fortune to talk to him-we enjoyed remembering the MIT Math Department of Wiener and Levinson and Lin. He passed away at the age of 96.

I was always grateful to him, and now it is a special honor to visit Tsinghua. I chose to speak partly about my experience of preparing video lectures on linear algebra. I want to encourage others to think (and to act!) in this direction too-it can change your life. I will also describe a sequence of ideas that could help to complete large matrices when data is missing, and to compute with those matrices when the size of the data is overwhelming.

\section{OpenCourseWare and Online Teaching}

My principal courses at MIT are 18.06 Linear Algebra and 18.085 Computational Science and Engineer-

* Department of Mathematics, Massachusetts Institute of Technology, Cambridge, Mass., U.S.A.

E-mail: gs@math.mit.edu ing. One is for undergraduates, with 250 students in Spring 2015. The other is for graduate students, with 125 students in Fall 2014. At some time in the 20th century I was asked to reorganize these subjects. At that time linear algebra was studied by a small group of math majors (which once included me-I liked it but we almost never saw a matrix). And the equivalent to 18.085 never saw a computer. This had to change-without losing the mathematical content.

The new courses needed new textbooks: Linear Algebra and Its Applications (1976 ... 2006) was followed by Introduction to Linear Algebra (WellesleyCambridge Press, 1993 ... 2009). A Chinese translation of that second book is just completed. For the graduate course, Introduction to Applied Mathematics (1986) was followed by Computational Science and Engineering (2007). And now there are video lectures; those are my subject today.

MIT's OpenCourseWare was a new answer to an old question: How to help students outside the classroom? It was the right answer-to make the lectures free for everyone. There are 2000 MIT courses on ocw.mit.edu, many with videos. They show MIT as it is.

The new problem in 2015 is to go further. OCW led to MITx (on campus) and edX (worldwide) with homeworks and exams and grades and certificates. The 18.06 homeworks are now graded by computer, with instant response that students like. We have not yet offered an edX course on linear algebra (a MOOC = Massive Open Online Course).

The linear algebra course was filmed in my normal class with normal mistakes; you could look at Lecture 10. Probably 4,000,000 viewers have watched, and quite a large subset has sent email! I especially wanted to provide a version with Chinese subtitles. 